\title{
THE SOIL INFORMATION SYSTEM OF RWANDA: A USEFUL TOOL TO IDENTIFY GUIDELINES TOWARDS SUSTAINABLE LAND MANAGEMENT
}

\section{Ann Verdoodt \& Eric Van Ranst}

Laboratory of Soil Science

Ghent University

Krijgslaan 281 (S8)

9000 Gent

Belgium

e-mail: ann.verdoodt@ugent.be

\section{SUMMARY}

The soil information system of Rwanda: a useful tool to identify guidelines towards sustainable land management.

On the steep lands of Rwanda, overpopulation and degradation of the land resources are acute problems, especially against the background of present and future populations, food and agricultural demands, and opportunities and constraints. The ability of the land to produce is limited with the limits to production being set by climate, soil and landform conditions, and the use and management applied. Knowledge of the soils, their properties and their spatial distribution, is indispensable for the agricultural development of Rwanda as it 
opens opportunities for a more rational management of the land resources. The necessary input data for this agricultural research mainly became available through the realization and updating of a soil information system. Geographic information science and relational database software were combined to capture the spatial as well as the numerical and descriptive data gathered during the national, traditional soil survey that was finalized in 1989. The database was further extended with topographic and climatic data and has been used to characterise the physical production environment that farmers face in the different agricultural regions of the country. Several land evaluation tools, adapted to the Rwandan environment, have subsequently been developed, evaluating the options for stronger crop regionalisation, the strategies for more rational regional land use planning, and the possibilities for further intensification of the crop production.

Key Words: Soil Survey, Geographic Information Science, Land Evaluation, Crop Growth Modelling, Rwanda

\section{INTRODUCTION}

Rwanda's main aim of the Millennium Development Goals is to reduce underdevelopment and poverty by achieving economic growth. Given that agriculture is the main productive activity for the majority of the Rwandan households and dominates the country's Gross Domestic Product (GDP), the attention accorded to the development of the agricultural sector cannot be over-emphasized (Rwanda Development Gateway, 2005).

In this small and very densely populated country, food production is insufficient to feed the population. Land scarcity has compelled farmers all over the country to depart from their traditional system and convert pastures and woodlots into cropland and cultivate fragmented, fragile, steep-sloping fields (Clay, 1996). Other characteristics of the subsistence agriculture in Rwanda are the lack of individual and regional specialisation, a weak integration between agriculture and the economic markets, and an important dependence on the climatic conditions (Imerzoukene and Van Ranst, 2001). Erosion and nutrient 
mining result in a serious decrease of the physical and chemical soil fertility and affect crop yields.

The government recognized the environmental threats and food insecurity and developed an agricultural sector strategy that aims to increase rural incomes, enhance food security, and convert agriculture into a viable sector by moving away from subsistence to market-based activities. The strategy emphasizes the importance of:

- regional specialisation in order to profit from the environmental diversity of Rwanda and to maximise the yields of the most suitable crops in each region;

- diversification of the agricultural production in order to meet the national and international demands and integrate agriculture on the economic markets;

- intensification through the use of additional inputs (fertilisers) in order to increase the yields;

- optimal valorisation of all available land through feasible practices controlling the availability of water and nutrients;

- education of the farmers so that they are able to select relevant management options (Imerzoukene and Van Ranst, 2001).

This paper describes the soil information system of Rwanda and how it can provide guidelines on regionalisation, intensification and sustainable land use when integrated with different scale-dependent land evaluation tools.

\section{SOIL INFORMATION SYSTEM OF RWANDA}

The soil information system of Rwanda contains a set of maps at various scales and related numerical databases of soil data covering all of Rwanda. It serves as the national archive of the soil resources information that was collected during the national soil survey.

\section{National soil survey}

From 1981 to 1994, based on extensive use of aerial photographs and fieldwork, soil survey teams described the relationship between soil, landscape and land use in several pilot zones throughout the country. 
Following a judgemental sampling strategy, soil profiles were described and sampled up to a depth of 1 to $2 \mathrm{~m}$, or to an impermeable layer. Additionally, $0.5 \mathrm{~m}$ deep mini soil profiles extended by augering up to $1.25 \mathrm{~m}$, were described. Based on unique combinations of parent material, degree of weathering, soil depth, drainage and texture, the identified soils were regrouped into 276 soil series. This semi-detailed soil survey allowed the soil surveyors to associate sets of landscape features with sets of internal soil properties, and enabled them to visualize the pattern of the soils within each physiographic unit (Figure 1). The soil-terrain-land use relationship found in the pilot zones was extrapolated to other areas with similar properties by detailed interpretation of aerial photographs.

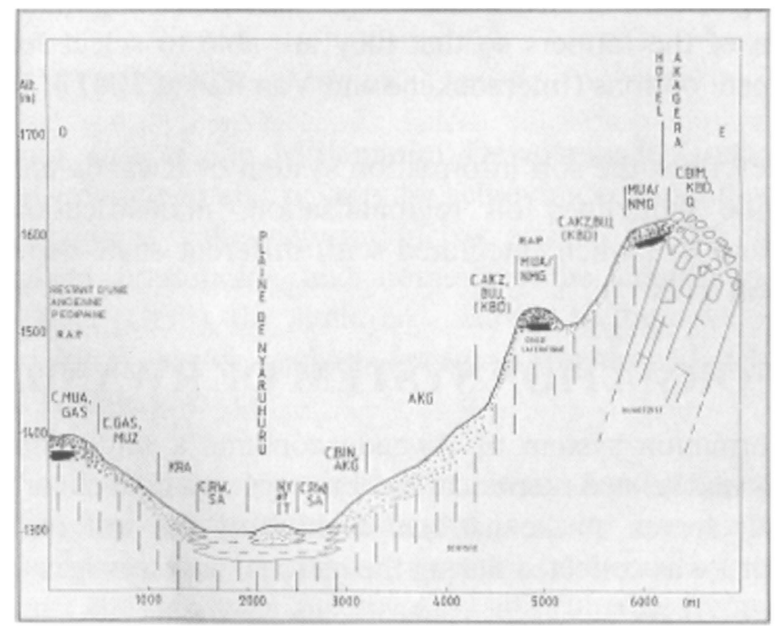

Figure 1: Example of a toposequence in eastern Rwanda, showing the general landform, the altitude, and the corresponding complexes of soil series (the capital letters indicated are abbreviations of the soil series names) 
During the survey, 2,000 profiles, and 25,000 mini-profiles and augerings had been described, and more than 100,000 analyses had been performed. The national soil survey resulted in the elaboration of a reconnaissance soil map at a scale of 1:250,000 and in 43 semidetailed soil map sheets, covering the national territory, at a scale of 1:50,000. The soil units are mainly complexes of soil series. A morphological, physical and chemical characterisation of these soil series was possible through the use of the profile and auger data (Verdoodt et al, 2004).

From 1989 onwards, the soil maps and all observation points with their corresponding data were stored in a master database using GIS (ESRI ArcInfo and ArcView) and database (Access) software. Stopped in 1994 due to the war in Rwanda, the digital storage of the soil data was later finalized at the Laboratory of Soil Science, Ghent University, Belgium (1998-2000). Both the activities in Rwanda and at Ghent University were financed by BADC (Belgian Administration for Development Cooperation).

\section{Database design}

The core of the soil information system consists of the 43 semidetailed soil maps, the corresponding explanatory notes and the soil profile database (Laboratory of Soil Science, Ghent University).

Auxiliary spatial data comprise the physiography, hydrography, the road network, and the administrative units, both at the reconnaissance and semi-detailed scales. Also a time-series average, monthly, climatic database of 192 meteorological stations distributed throughout the country, was imported in an Access database. 
Figure 2 illustrates the structure of the soil information system.

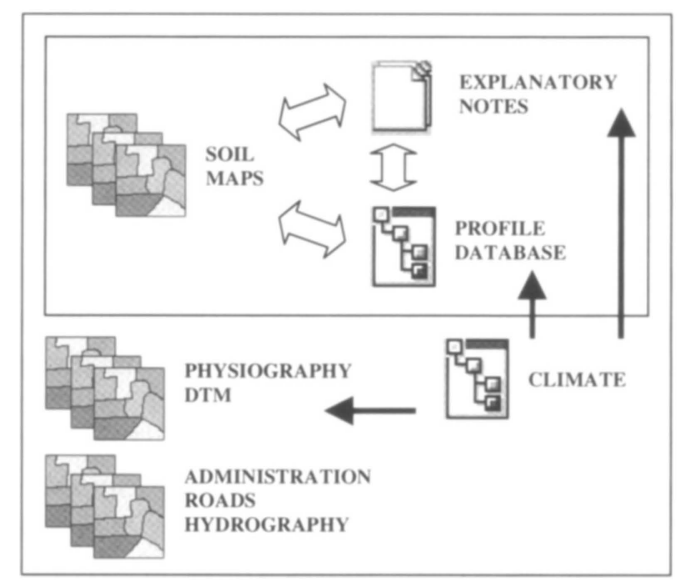

Figure 2: Structure of the Rwandan soil information system

Numerical data stored in the Access databases can be easily linked with the cartographic data stored in the ArcView projects, through the use of a common field. The unique profile number can be used to import numerical data about the profile into the project with the spatial distribution of the profiles. As such, new maps can be created, showing for instance the chemical and physical properties of the soil units.

\section{Soil maps}

The 43 soil maps and related attributes, drawn and characterised by different authors, were harmonised and the correlation with neighbouring map sheets was optimised.

Soil units were characterised by a colour pattern and a unique number, while the colour legend groups the different soil units according to their parent material, soil profile development, soil depth, drainage, soil texture and stoniness (Figure 3). 


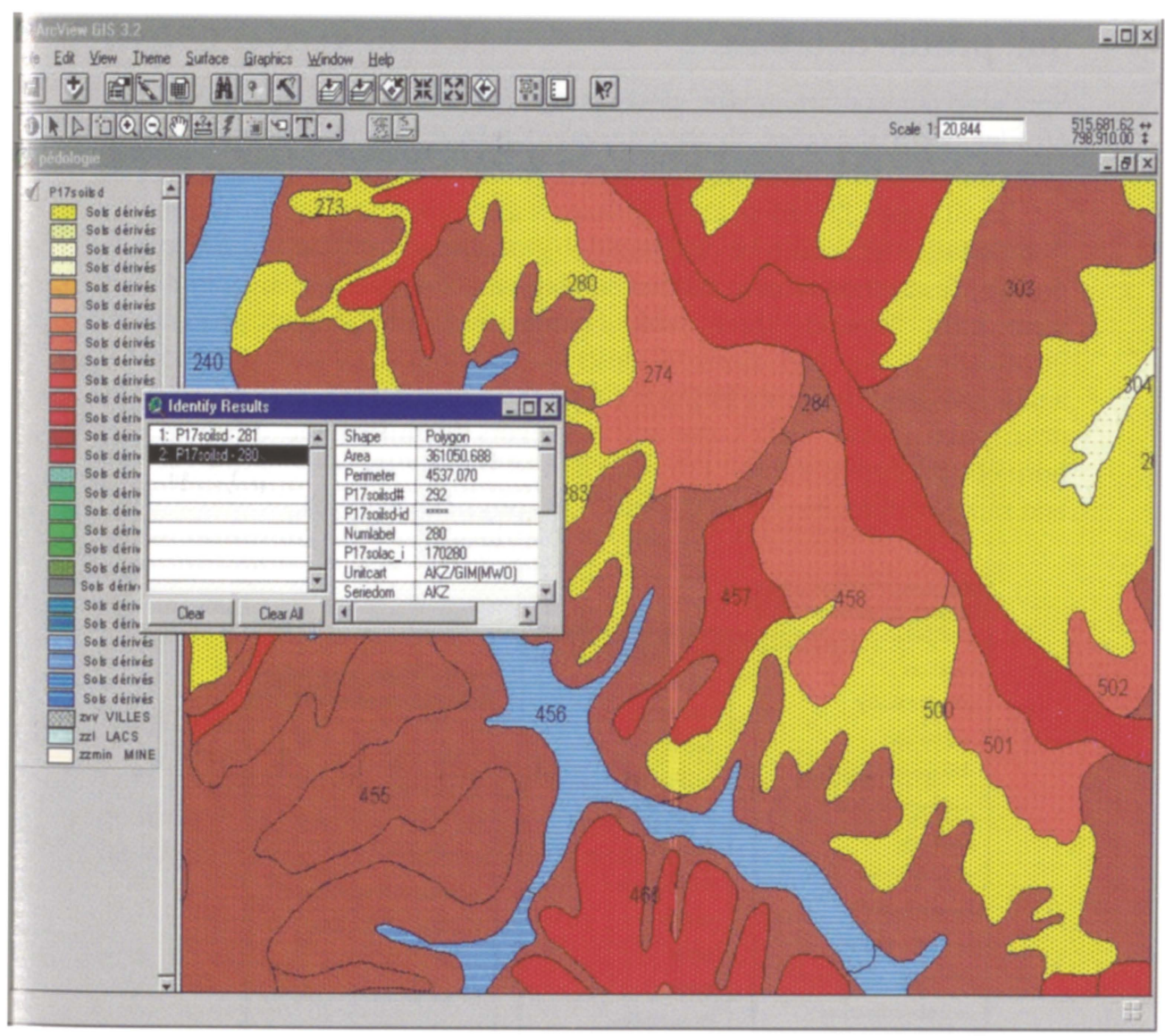

Figure 3: Detail of the soil map of Kigali at a scale of 1:50,000,

(Van Ranst et al., 2000). The unique number can be used to look up the name of the cartographic unit, its legend and the general properties of the soil series. These data have been summarised in the explanatory texts that complete the soil maps. In addition, a link can be made to the Access database, storing the descriptive and analytical data of all profiles belonging to a specific soil series. 


\section{Soil profile database}

Spreadsheets containing the description and analysis of 1,834 soil profiles were imported in the Access database. Figure 4 gives an overview of all the parameters recorded.

A code language had to be developed to store the information from the profile descriptions in a relational Access database. Relationships were built between three tables, containing the general profile information, the soil horizon descriptions, and the soil horizon analytical data. Basically following the FAO guidelines for soil profile description (FAO, 1977), the soil surveyors identified the different horizons present in the soil profile. These soil horizons were described and sampled for subsequent chemical and physical analyses.

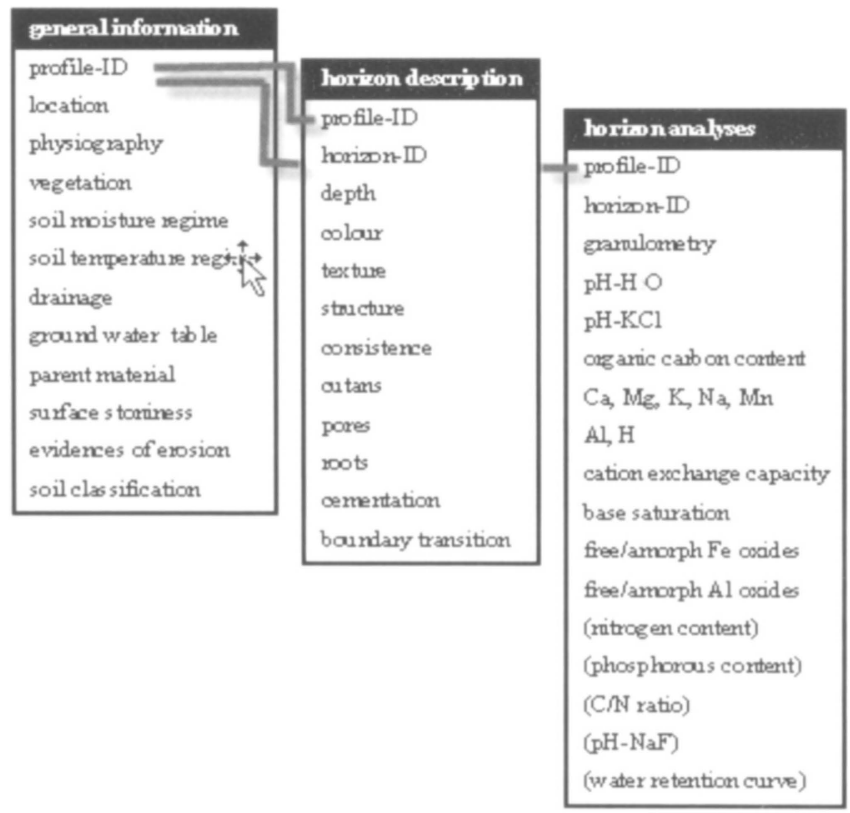

Figure 4: Contents of the soil profile database (parameters between brackets are recorded for a limited number of soil profiles). 


\section{Digital terrain models}

Also the $25 \mathrm{~m}$ interval contour lines of the hardcopy topographical maps were scanned, vectorised, geo-referenced, and coded. Digital terrain models based on the topographic maps offer 3-D views (Figure 5) of the landscape characterising each of the 43 map sheets (Laboratory of Soil Science, Ghent University). Several GIS tools can be used to derive slope maps, toposequences, or to perform other analyses with regard to hydrology and erosion.

\section{OPTIONS FOR REGIONALISATION}

The diversity in climatic environments offers the Rwandan farmer the opportunity to cultivate temperate, humid tropical, or dry tropical crops, depending on the temperature and rainfall regime of his land. A stronger regionalisation, based on the selection of the most suitable climate and soil for each crop, is a main task of the new agricultural strategy.

\section{Methodology}

Land classification technology provides a framework for the qualitative assessment of this land suitability for a specific land use based on generally available soil survey data. 


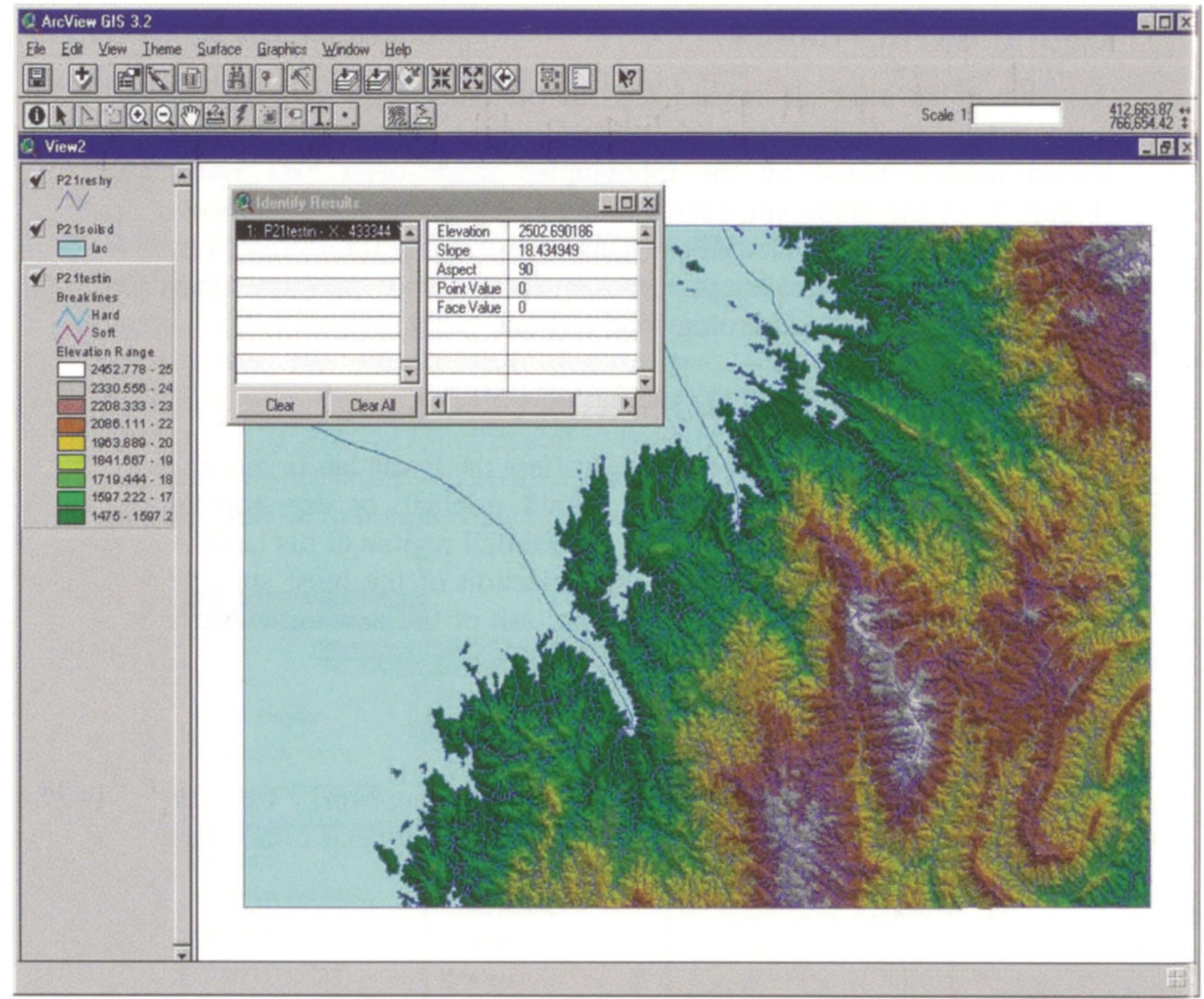

Figure 5: Detail of the digital terrain model of Kibuye at a scale of 1:50,000 (Van Ranst and Imerzoukene, 2001)

A land suitability classification classifies land according to its suitability for the cultivation of a specific crop through a comparison of the crop-specific requirements with the actual land characteristics. Introduction of management strategies controlling soil loss, internal drainage and fertility, allows assessment of both the actual and the potential land suitability. A flow chart of the different procedures has been illustrated in Figure 6 . 
Integration of expert knowledge and literature data with the natural resources database at scale 1:250,000 resulted in the design of a land suitability classification system for several crops, adapted to the environmental conditions in Rwanda (Verdoodt and Van Ranst, 2003a; Verdoodt and Van Ranst, 2006a).

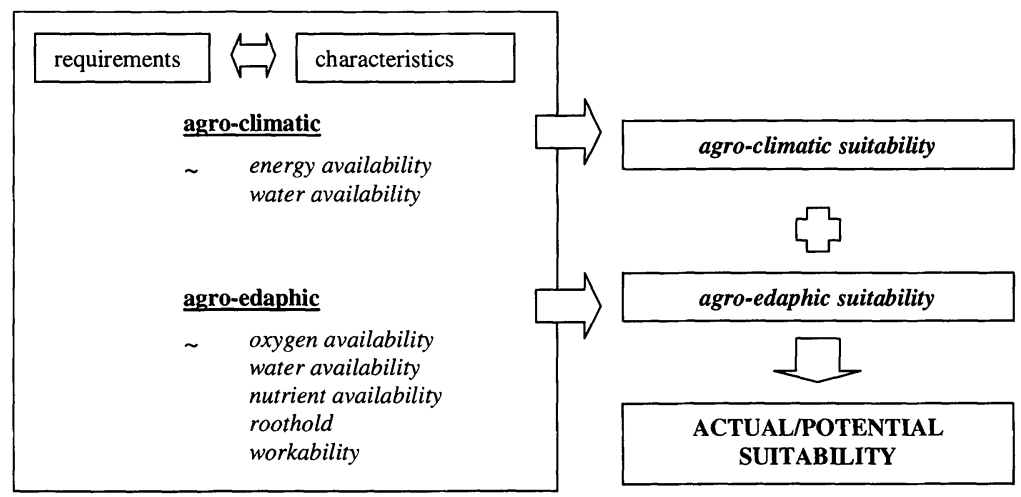

Figure 6: Flow chart of the land suitability classification procedure

The cereals sorghum and maize, the tubers cassava, sweet potato and potato, the legumes bean and pea, and the oil crops groundnut and soybean, are representative for the Rwandan subsistence agriculture. Also included in the analysis are the fruit tree banana and the cash crops tea and arabica coffee.

Definition of the crop requirements was based on the expert knowledge of the soil surveyors formerly active in the national soil survey project (Birasa et al., 1992) and on the requirements designed by Sys et al. (1993).

\section{Results}

Without going into detail with respect to the land suitability for each of the 12 crops, it can be concluded that the land suitability classification resulted in identifying clear options for regionalisation. 
From the actual land suitability classification it is clear that the main determinants for national crop selection are the temperature and rainfall regimes. Erratic rainfall in East Rwanda limits the production potential of crops sensitive to water stress. In mountainous western Rwanda, abundant rainfall leached most soils developing on nutrientpoor parent materials. The most important edaphic limitations to crop production in Rwanda are the slope gradient, soil depth and sum of exchangeable basic cations (nutrients). Where climatic conditions are optimal or near optimal, these soil properties will determine the spatial distribution of the final suitability. Important deviations from this general rule have been reported for crops that are very demanding (Arabica coffee), or for those that pose extremely low requirements to the soil (groundnut).

When evaluating the potential suitability for many crops in Rwanda, it turns out that reducing the risk of erosion and increasing or maintaining soil fertility, being two major management techniques of extreme importance in Rwanda, are generally much more responsive on the deep soils of the West, than on the old, strongly weathered or stony soils of the East, where inherent soil properties such as stoniness and low cation exchange capacity set a limit to the potential production. This doesn't mean that these soils have not at all the potential of producing well. However, for maintaining the same chemical fertility level, much higher investments will be required, while a smaller range of crops will be suited. In the lowlands, inherent physical or chemical properties often limit the potential suitability. 


\section{OPTIONS FOR REGIONAL LAND USE PLANNING}

The enormous variability in landscape and soil properties, affecting the physical and chemical soil fertility, influences regional crop productivity.

\section{Methodology}

For estimating the land productivity at regional scale, semiquantitative land evaluation tools are most appropriate. The three hierarchical crop growth model, described by Tang et al. (1992) and Van Ranst (1994) has proved to be useful to land evaluators and planners, especially in developing countries where massive data are very often missing. This model applies both quantitative and qualitative approaches to estimate crop yield attained on the different land units.

Crop production is described in terms of radiation-thermal (RPP), water-limited (WPP) and land production potentials (LPP), as presented in Figure 7. The levels are in fact nested crop production systems, starting with the highest, potential or radiation-thermal production related to optimal conditions, and working down to production levels at sub-optimal conditions regarding water and nutrient supply.

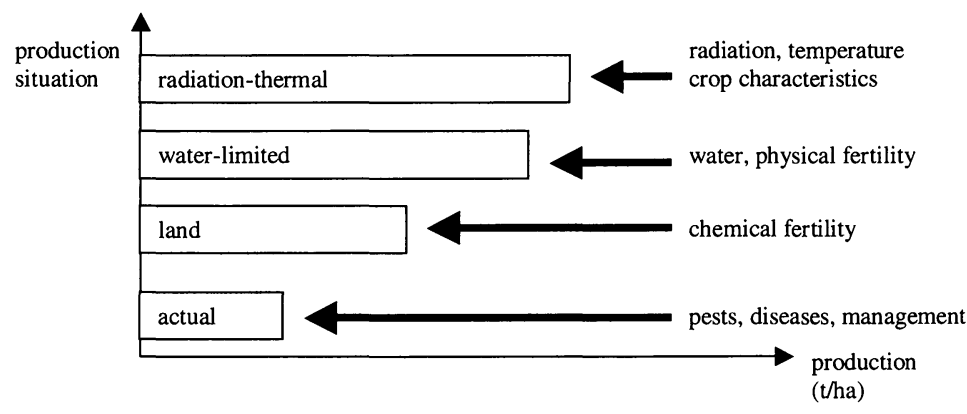

Figure 7: Production situations in hierarchical crop simulation models 
Estimation of the potential production of a crop under optimal conditions of water and nutrient supply is based on the biomass production model developed by the FAO in 1979. The impact of water stress on crop growth is quantified through the estimation of actual and maximum evapotranspiration from a simple single-layered water balance working at a 10-day time-step. A crop specific yield response factor subsequently translates the relative evapotranspiration deficit into a yield deficit, resulting in an estimation of the water-limited production potential. Determination of the land production potential as affected by the chemical soil fertility is based on the calculation of numerical ratings for apparent cation exchange capacity, $\mathrm{pH}$, sum of exchangeable basic cations and organic carbon following the qualitative approach depicted in the land suitability classification.

Application of this land evaluation technology in Rwanda has been performed in the agricultural zones of the Bugesera (Vekeman, 2002) and Mayaga (Goethals, 2002), using the monthly climatic database of the individual meteorological stations located inside or near the study areas, together with the corresponding soil map sheets at scale 1:50,000. Each selected map unit was characterised by the analytical data of the representative soil profile. The topographic maps were converted into a slope map using GIS technologies.

\section{Results}

The use of the 3-level crop production model allows the researcher to estimate crop yields and to identify the relative importance of the different production factors, taking into account climate, soil and landform.

The crop growth model has been run for six regionally important crops - sorghum, common bean, soybean, sweet potato, groundnut and banana. Given the variability in slope gradient, water holding capacity and chemical fertility of the fifteen different soil series present in the study area, a multitude of productivity estimations has been generated for each of these field crops. Figure 8a illustrates the estimated sorghum production at the three different production levels for two different soil series with a slope gradient between 0 and $5 \%$. The 
impact of the slope gradient on sorghum productivity is shown in Figure 8b.

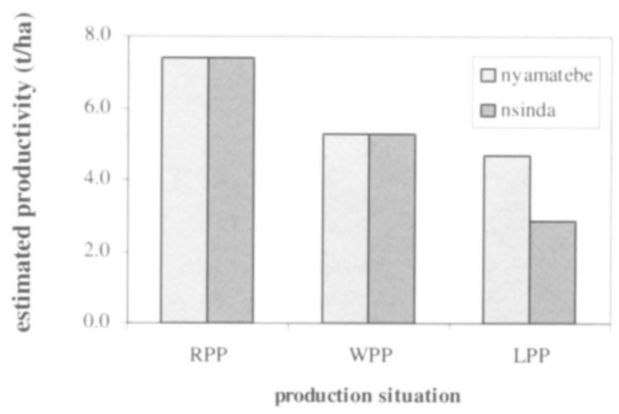

(a)

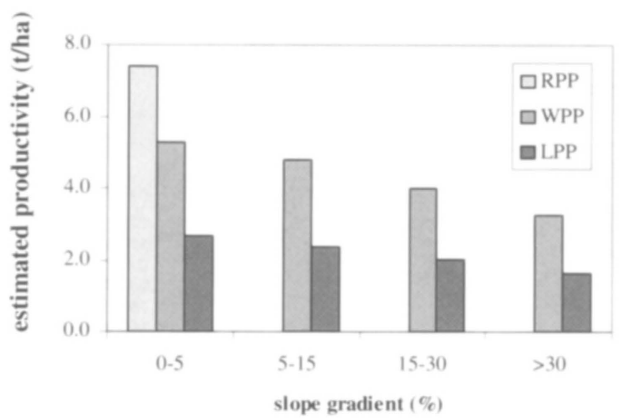

(b)

Figure 8: Estimated sorghum productivity at different production situations in the Bugesera (a) when cultivated on two different soil series - Nyamatebe and Nsinda and (b) as a function of the slope gradient using an average reduction factor for chemical soil fertility

The irregular rainfall distribution with the occurrence of two dry seasons limits rainfed crop production in both the Bugesera and the Mayaga. Especially on steep hillsides, where a large fraction of the precipitation is lost through run-off, the yield deficit is considerable.

The most important limiting factor with respect to the chemical soil fertility is the generally high acidity. Frequently, the $\mathrm{pH}$ drops below 5.5 and sensitive crops suffer from Al-toxicities. According to the 
3-level crop growth model, the best yields can be expected in the valleys. Figure 9 shows the spatial distribution of the land production potential of common bean cultivated in the Bugesera.

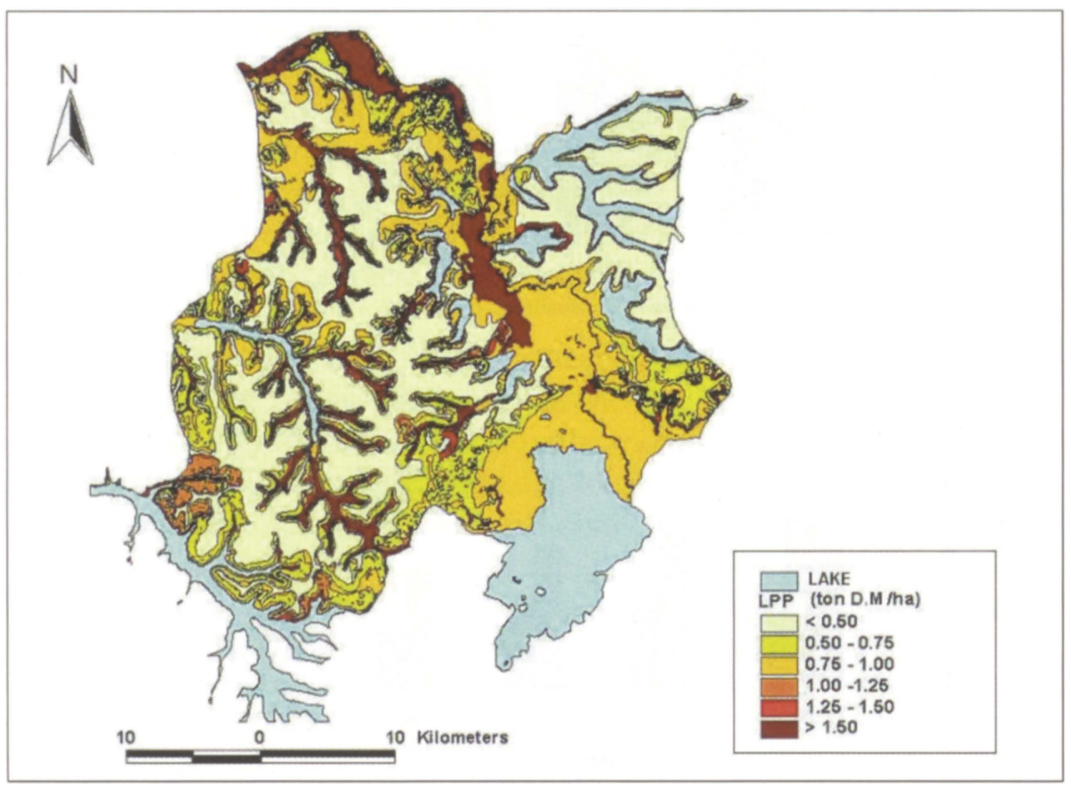

Figure 9: Spatial distribution of the land production potential of common bean in the Bugesera (Verdoodt et al., 2004)

Comparison of the estimated crop productivity in the Bugesera with recorded data, indicated that the crop production model performed quite well. A reasonable estimate of the crop yield could be made, while the quality of the people's diet could be evaluated. 


\section{OPTIONS FOR INTENSIFICATION}

In view of looking for solutions to the current problems in the Rwandan agriculture, a new model has been elaborated describing crop growth at a daily temporal scale.

\section{Methodology}

DAICROS (DAily CROp growth Simulator) simulates the daily dry matter production of annual field crops (Verdoodt and Van Ranst, 2003b; Verdoodt et al., 2004). From a conceptual point of view, DAICROS is made up of a number of original parts such as the daily simulation of the leaf area index (LAI), but most of the remaining parts are based on conventional formalisations or have been taken from existing models such as SUCROS (van Lanen et al., 1992) and WOFOST (WOrld FOod Studies) (Supit et al., 1994). For the elaboration of DAICROS, this modelling approach has been simplified in order to be applicable in most tropical environments, where field trials, offering plant characteristics and responses to be used in the crop growth models, are limited. Actually, the model consists of two hierarchical production situations: the radiation-thermal production potential (RPP) and the water-limited production potential (WPP).

Simulation of the gross photosynthesis rate involves among others, assessment of the maximum photosynthesis rate at light saturation, description of the photosynthesis light response of a fully developed canopy and simulation of the leaf area index. Within the respiration module, maintenance respiration losses are quantified together with the conversion efficiency of the net primary assimilates into crop dry matter, reflecting growth respiration losses. Leaf growth is simulated using a strongly simplified model based on the leaf area index at maximum growth rate and the characterisation of four leaf growth stages including fast linear growth during the vegetative stage and exponential decay at the end of the crop cycle (Verdoodt and Van Ranst, 2003b; Verdoodt et al., 2004).

Estimation of the WPP is essentially based on the quantification of the actual crop transpiration rate. In order to reveal the impact of erratic 
rainfall on crop productivity, the water balance approach has been thoroughly revised. The temporal scale is refined up to a daily level. Both the impact of water and oxygen stress is simulated in a multilayered soil profile with a depth-dependent water uptake capacity of the roots. This DAily, MUlti-layered WAter Balance (DAMUWAB) simulates water movement within the soil based on the tipping-bucket principle in order to reduce the required hydraulic soil properties. Integration of DAICROS with DAMUWAB yields the water-limited production potential (Figure 10). Water and oxygen stress affect the actual transpiration rate, the gross photosynthesis rate and leaf growth (Verdoodt and Van Ranst, 2003b; Verdoodt et al., 2005, Verdoodt and Van Ranst, 2006b).

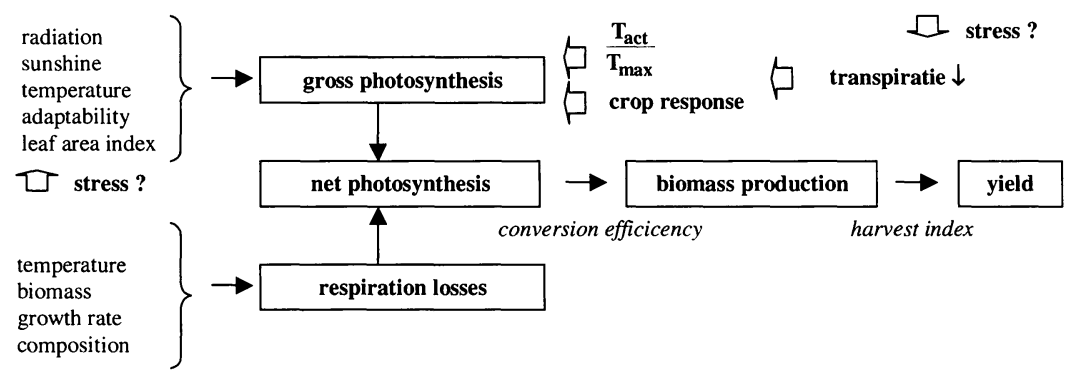

Figure 10: Overview of the DAICROS calculation procedures (Verdoodt et al., 2005)

Sensitivity analysis and validation have been performed using the daily climatic data, gathered for a limited set of 6 meteorological stations, and the soil profile database of Rwanda. As such, the RPP and WPP of groundnut, common bean, maize, sorghum and white potato have been estimated when grown on 6 locations that are strongly different from a climatic and edaphic point of view.

Integration of DAICROS with DAMUWAB allows simulation of the impact of daily crop growth and productivity on freely drained soils under rainfed conditions. The numerous graphs created during the program flow, clearly illustrate the impact of temperature, rainfall distribution, slope gradient, soil depth, soil water holding capacity and 
management practices - the crop and sowing date selection - on the productivity of cereals, tubers, legumes, and oil crops when grown in the lowlands, middle altitude regions and highlands of Rwanda. Without giving a detailed discussion on all obtained results and conclusions, the following paragraphs illustrate some of the features of this daily crop growth model.

\section{Results}

Significant differences in total rainfall amounts, rainfall distribution and water retention properties of the soil series affect the daily uptake of soil water by the developing root system from the exploited soil compartments of the multi-layered water balance. A moderate rainfall event after a dry period moistens only the upper soil compartments, while the growing crop can rely on the replenished soil water reserves during the months of November and April to overcome dry weather. A part from crop-specific characteristics, the actual transpiration rate of the crop strongly depends on this water supply.

Figure 11 illustrates the daily rainfall together with the actual and maximum transpiration rate of common bean cultivated near Karama during the agricultural season A of 1978. Quantification of the crop transpiration allows estimation of the daily gross photosynthesis rate. Subtraction of the daily respiration losses yields the daily biomass production rate and daily cumulative dry matter. 


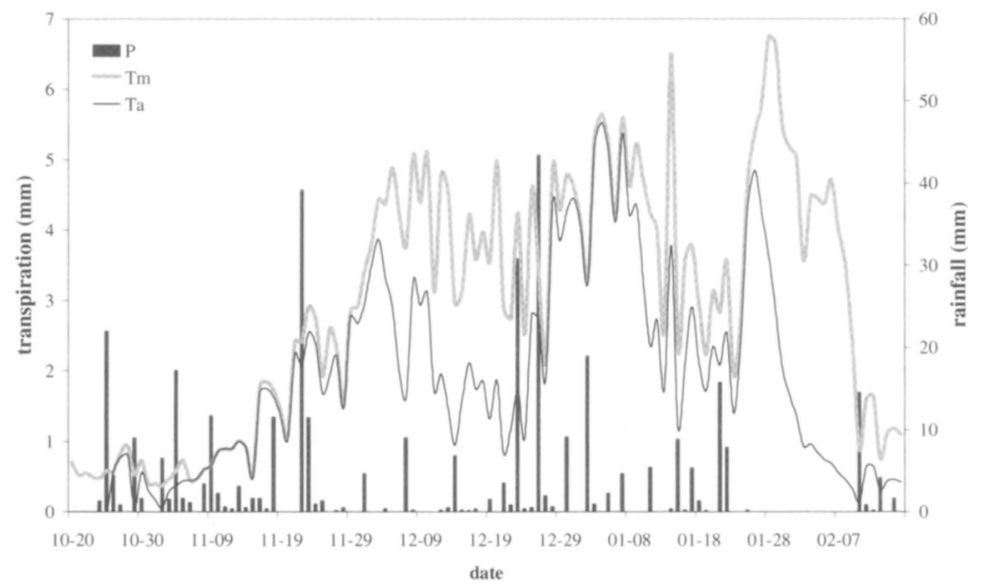

Figure 11: Rainfall (P), maximum (Tm) and actual (Ta) daily transpiration of common bean, cultivated during season A of the agricultural year 1978 near Karama

Farmers face a dilemma when determining the optimal sowing date for the crops of the main agricultural seasons. The start of the short rains in September-October is strongly variable. Delay of the sowing date until regular rainfall events guarantee a sufficient water supply may give water stress conditions during the flowering period if this coincides with the short dry season. Generally, sufficient soil water reserves simplify the choice during the second season, but adverse climatic conditions may equally reduce the production potentials.

The soil water reserves and the length of the crop cycle not only affect the sowing date, but also determine the possibilities for the cultivation of two crops in sequence on the same field. According to DAMUWAB, water availability limits the success of the practice in the lowlands, while a too long crop cycle limits the practice in the highlands, except for potato. At middle altitudes, the feasibility depends on the rainfall distribution. This largely corresponds to the real-world conditions. 
Next to the crop cycle duration, also other parameters such as the crop coefficient, yield response factor and water extraction factor influence the response of the crop to the water supply. Sorghum exceeded all other crops by far in water stress tolerance when cultivated in the deep soils of the lowlands and middle altitudes. Potato, on the other hand, required most water and could only be cultivated successfully on the recent volcanic soils near Musanze.

Comparison of the modelling results with the reported yield data revealed a satisfactory model performance with respect to common bean, sorghum and potato, while the simulated yields of groundnut and maize were overestimated. A better knowledge of the crop parameters, with special attention to the crop cycle duration is required in these two cases.

\section{CONCLUSIONS}

The suitability classification developed for application in Rwanda performs very well. It is an interesting tool for the analysis and description of important climatic and edaphic properties affecting agricultural production. The crop-specific suitability classification succeeds in giving a sound overview of the suitability of the different agro-climatic regions at a scale of 1:250,000.

Whereas qualitative land evaluation methods are useful tools in the research for regionalisation and diversification of the agriculture, they are incapable of simulating the impact of the small-scale temporal and spatial changes in climate, topography, soil and management within mountainous Rwanda. Application of the multiple-step crop growth model described by Tang et al. (1992) in Rwanda, though successfully applied for the assessment of the agricultural production potential in many tropical countries, highlighted some serious limitations with respect to the simulation of the soil water balance during periods of erratic rainfall.

The erratic rainfall and high variability in soil properties that occurred within most soil units, further stressed the importance of designing a fine-tuned crop growth model. The resulting DAICROS model runs 
with a relevant time step without significantly increasing the demands for input parameters. Repeated model runs for different crops growing under different climatic and edaphic conditions illustrate the impact of the physical environment on crop growth. Next to the spatial yield variability, the model is capable of illustrating the high temporal variation in production recorded in several consecutive agricultural seasons and years. In addition, also the influence of management decisions on the final output is quantified.

Combined with these land evaluation tools, the soil information system of Rwanda thus proves a useful tool to support the new agricultural policy decision-makers.

\section{BIBLIOGRAPHY}

BIRASA, E.C., BIZIMANA, I., BOUCKAERT, W., GALLEZ, A., MAESSCHALCK, G., \& VERCRUYSSE, J., 1992. Carte d'aptitude des sols du Rwanda. Carte Pédologique du Rwanda. CTB et MINAGRI, Kigali, 76 p.

CLAY, D.C., 1996. Fighting an Uphill Battle: Population Pressure and Declining Land Productivity in Rwanda. MSU International Development Working Paper 58. Michigan State University, East Lansing, 28 p.

DELEPIERRE, G., 1974. Les Regions Agricoles du Rwanda. Note technique 13. ISAR, Butare, $24 \mathrm{p}$.

FAO, 1977. Guidelines for soil profile description. 2nd ed. Soil Resources Development and Conservation Service, Land and Water Development Division, FAO, Rome.

FAO, 1979. Report on the Agro-ecological zones project: Vol. 1, Methodology and results for Africa. World Soil Resources Report 48. FAO, Rome.

GOETHALS, T., 2002. Characterisation of the Physical Environment and Evaluation of the Agricultural Production Potential in the Mayaga, Rwanda. Masters Thesis. Interuniversity Programme in Physical Land Resources, Ghent University, Ghent, $123 \mathrm{p}$.

IMERZOUKENE, S., \& VAN RANST, E., 2001. Une banque de données pédologiques et son S.I.G. pour une nouvelle politique agricole au Rwanda. Bull. Séanc. Acad. R. Sci. Outre-Mer 47 (3): 299-329.

RWANDA DEVELOPMENT GATEWAY, 2005. AGRICULTURE. Online document created 31/01/2005, assessed 17/08/2006.

Link: http://www.rwandagateway.org/article.php3?id_article=71\&lang 
SUPIT, I., HOOIJER, A.A., \& VAN DIEPEN, C.A., 1994. System description of the Wofost 6.0 crop simulation model implemented in CGMS. Volume 1: Theory and Algorithms. European Commision, Luxembourg, 144 p.

SYS, C., VAN RANST, E., DEBAVEYE, J., \& BEERNAERT, F., 1993. Land Evaluation. Part III: Crop requirements. Agricultural Publications 7. General Administration for Development Cooperation, Brussels, $199 \mathrm{p}$.

TANG, H., VAN RANST, E. \& SYS, C., 1992. An Approach to Predict Land Production Potential for Irrigated and Rainfed Winter Wheat in Pinan County, China. Soil Technology 5: 213-224.

VAN LANEN, H.A.J., VAN DIEPEN, C.A., REINDS, G.J. \& DE KONING, G.H.J. 1992. A comparison of qualitative and quantitative physical land evaluations, using an assessment of the potential for sugar-beet growth in the European Community. Soil Use and Management 8 (2): 80-89.

VAN RANST, E., 1994. Modelling land production potentials - A new wave in land suitability assessment. In: New waves in soil science. Refresher course for alumni of the International Training Centre for Post-graduate Soil Scientists of the Ghent University. Harare, University of Zimbabwe. Publications series 7. ITC, Ghent, 356 p.

VAN RANST, E., DELVAUX, B., BAERT, G., IMERZOUKENE, S., JAMAGNE, P., NDAYIRAGIJE, S., \& PINEROS GARCET J., 2000. Carte Pédologique de Kigali ( 1 :50,000), feuille 17 Kigali. Laboratoire de Pédologie, Gand. ISBN 90-76769-17-6.

VAN RANST, E. \& IMERZOUKENE, S., 2001. Carte du Relief du Rwanda (1:50 000), feuille 21 Kibuye. Laboratoire de Pédologie, Gand. ISBN 90-76769-65-6.

VEKEMAN, V., 2002. Fysische landevaluatie voor het inschatten van de bevolkingsdraagkracht in de Bugesera (Zuid-Rwanda). Ingenieursthesis. Faculteit Landbouwkundige en Toegepaste Biologische Wetenschappen, Universiteit Gent, Gent, 222 p.

VERDOODT, A. \& VAN RANST, E., 2003a. Land Evaluation for Agricultural Production in the Tropics. A Large-Scale Land Suitability Classification for Rwanda. Laboratory of Soil Science, Ghent University, Gent. 175 p.

VERDOODT, A. \& VAN RANST, E., 2003b. Land Evaluation for Agricultural Production in the Tropics. A Two-Level Crop Growth Model for Annual Crops. Laboratory of Soil Science, Ghent University, Ghent, 258 p.

VERDOODT, A., VAN RANST, E., \& YE, L., 2004. Daily simulation of potential dry matter production of annual field crops in tropical environments. Agronomy Journal 96: 1739-1753. 
VERDOODT, A., VAN RANST, E., \& VERPLANCKE, H., 2004. Integration of Soil Survey Data, Geographic Information Science and Land Evaluation Technology for Land Use Optimisation in Rwanda. In: Eswaran, H., Vijarnsorn, P., Vearasilp, T. and Padmanabhan, E. (ed.). Innovative Techniques in Soil Survey: "Developing the foundation for a new generation of soil resource inventories and their utilization". Land Development Department, Bangkok, Thailand, p. 365-380.

VERDOODT, A., VAN RANST, E., YE, L., \& VERPLANCKE, H., 2005. A daily multi-layered water balance to predict water and oxygen availability in tropical cropping systems. Soil Use and Management 21: p. 312-321.

VERDOODT, A. \& VAN RANST, E., 2006a. Environmental assessment tools for multi-scale natural resources information systems. A case study of Rwanda. Agriculture, Ecosystems and Environment 114: p. 170-184.

VERDOODT, A. \& VAN RANST, E., 2006b. A Functional Crop Growth Model to Reveal Soil-Water-Plant-Environment Interactions under Different Climatic, Edaphic and Management Conditions in Tropical Cropping Systems. Paper presented during the $18^{\text {th }}$ World Congress of Soil Science, July 9-15, Philadelphia, USA. 